Mr. JoHnson: The point that Dr. Wesson brings up is extremely important. I think we ought to use our influence to induce them to have the oil emptied from the tank car and thoroughly mixed in the tank at the refinery in order to procure an accurate sample.

Mr. Perry: I would like to say this, too: that in sampling at the mill, if a mill starts loading a tank of crude oil, perhaps the foots or settlings are all at the bottom. It seems that to unload it where there is agitation, and sample it, is the only possible solution.

Mr. REESE: I would endorse the unloading of the tank very strongly, but I would not endorse mixing the settlings in with the oil if there is excessive settling in the tank on account of the much increased loss entailed by the mixing of settlings with the oil above what there would be from taking the oil and settlings separately and making a separate settlement on a foots basis.

Mr. Perry : Mr. President, I want to add this to the recommendation for the rules: "Any meal should be left in the tank and sampled separately and adjustment be made for same independent of the oil."

Note: This was followed by a lengthy discussion of different types of samplers, which, while very interesting and instructive, cannot be printed because of limited space now allowed us each month. A motion to adopt the committee's printed report without recommending any special form of sampler finally prevailed.

\section{A. O. C. S. STANDARD REAGENTS}

By Herbert S. Bailey, Chairman, Analytical Program

As announced in the November Chemists' Section, the Society has now ready for distribution Standard Sodium Carbonate and Ammonium Sulphate. These reagents were made by the General Chemical Company in accordance with specifications furnished by $\mathrm{H}$. C. Moore, chairman of the Ammonia Committee. They have been analyzed by three of our best chemists with the following results:

Sodium Carbonate

"A" reports 99.90 after ignition to dull redness.

" $\mathrm{B}$ " reports 99.97 on moisture-free basis.

"C" reports 99.91 after heating to dull redness.

Average taken as standard value $=99.93 \% \mathrm{Na}_{2} \mathrm{CO}_{3}$.

Ammonium Sulphate

\author{
"A" reports $25.70 \% \mathrm{NH}_{3}$ \\ "B", reports 25.64 " " \\ "C" reports 25.67 \\ Average taken as standard value $=25.67 \% \mathrm{NH}_{3}$
}

These values have been determined by several different standard methods, and the single values reported are the average of a number of determinations made by each chemist.

The price of fifty cents per sample announced last month does not include postage, and as these reagents are being sold at cost it is requested that those remitting with their order add ten cents per sample to cover this item.

The total cost of the reagents to the Society was over $\$ 650$, and as this was paid from the Cooperative Analytical Program funds, these are now sadly depleted. It is earnestly requested that members order at once as large a supply of the reagents as they can use, so that our funds for handling check meal and other reports may be speedily replenished.

Address all orders to Herbert S. Bailey, Head Laboratory, Southern Cotton Oil Co., Savannah, Ga., and make checks payable to Herbert S. Bailey, chair-

\section{MAKING ROUTINE WORK 100 PERCENT EFFICIENT}

By T. L. Roettger, S. C. O. Co., Head Laboratory, Savannah, Ga.

At the Head Laboratory of the Southern Cotton Oil Co. a few years ago we considered 300 ammonia determinations a full day's work for three chemists. Last year, however, our work increased to such proportions that it was necessary to get out as many as 500 ammonia results a day. This was done by one chemist and two assistants in eight and a half working hours and with the same general equipment as that used in former years.

While few laboratories are called upon to meet such a situation an outline of the arrangement of equipment, the time-saving methods and the system that enabled us to master our difficulties may be suggestive of ways for solving the routine analytical problems of others.

LABORATORY LAYOUT: The apparatus and general equipment of Head Laboratory for ammonia work are similar to those found in many of the large plant and commercial laboratories in the south. (1) For handling the Kjeldahl flasks wooden sticks about an inch square, a little less than three feet long, are used. These have six small spring steel clips, which just fit the necks of the flasks, fastened along one edge. The apron of the balance table is perforated with a series of half a dozen, inch square, holes into which one end of the sticks are slipped while the samples are being weighed. A similar set of ten holes along the edge of an adjacent work table make it possible to prepare sixty flasks with the sulfate and copper before they are transferred to the balance table. (2) The strong acid is added to the flasks still held on the sticks as these run along on a small roller truck beneath the liter acid burette. To fill the burette it is only necessary to open a stopcock at the end of an iron pipe syphon which dips into the carboy of acid supported on a heavy table above the burette. (3) The digestion bank is a series of Gilmer electric heaters set in front and below the lead pipe fume collector. Opposite each heater in the large pipe is a $34^{\prime \prime} \times 2^{\prime \prime}$ nipple which has a ${ }^{I} / 8^{\prime \prime}$ hole through it. These holes are small so that the suction supplied by the exhaust pan will be evenly distributed along the entire 20 feet of the pipe and also make it unnecessary to stopper any openings not in use to secure good draft on the rest. (4) The stills are the common type of perpendicular pipe condensers with Gilmer heaters. There are three sets of these, each with a capacity for twenty flasks, and they are placed in a line parallel to the digestion bank leaving only a small isle between. (5) The ammonia distiliate is collected in pint milk bottles which are handled from the time they are washed until set in place beneath the stills in sacks provided with hinged covers. The covers close around the neck of the bottles leaving the tops open for draining or filling with standard acid and indicator. Suitable racks for these cases are provided beneath the table where the acid is added and in these racks they remain upside down, after washing until needed. (6) For charging the milk bottles with the proper amount of standard acid a double attomatic pipette is used, the indicator is added from a stock bottle on the shelf above through a syphon and rubber tube with a bead closure and the water from a perforated copper pipe ring that just fits inside the top of the bottle. (7) The final titration is made with a $10 \mathrm{c.c}$. burette which is filled through the usual side arm at the bottom. A table from which the percentage of $\mathrm{NH}_{3}$ corresponding to the burette reading is hung alongside the burette and standard works-forms for recording results are always used. (8) In the bottom of one wash sink for cleaning the Kjeldahl flasks there is a manifold 